\title{
Insulin Increases The Central-To-Peripheral Arterial Stiffness Gradient in Response To Hyperglycemia in Healthy Humans: A Randomized Four-Way Crossover Study
}

\author{
William B Horton ( $\square$ WBH2N@virginia.edu ) \\ University of Virginia School of Medicine https://orcid.org/0000-0001-8081-1214 \\ Linda A Jahn \\ University of Virginia \\ Lee M Hartline \\ University of Virginia \\ Kevin W Aylor \\ University of Virginia \\ Eugene J Barrett \\ University of Virginia School of Medicine
}

Original investigation

Keywords: Insulin, Hyperglycemia, Octreotide, Vascular stiffness, Aorta

Posted Date: September 22nd, 2020

DOI: https://doi.org/10.21203/rs.3.rs-72339/v1

License: (c) (i) This work is licensed under a Creative Commons Attribution 4.0 International License.

Read Full License 


\section{Abstract}

Background: Increasing arterial stiffness is a physiological feature of vascular aging that is accelerated by conditions that enhance cardiovascular risk, including diabetes mellitus. Emerging evidence demonstrates that reversal of the normal central-to-peripheral arterial stiffness gradient predicts adverse cardiovascular consequences, including target organ damage. Preferential stiffening of central over peripheral arteries has been reported in type 2 diabetes, though mechanisms for this remain unclear.

Methods: We tested the effect of acutely increasing plasma glucose, plasma insulin, or both on central arterial stiffness (carotid-femoral pulse wave velocity) and peripheral arterial stiffness (radial artery augmentation index) in a randomized, four-way, crossover study of 19 healthy young adults. We also measured myocardial oxygen supply-demand (subendocardial viability ratio) and hemodynamic function.

Results: Carotid-femoral pulse wave velocity increased during hyperglycemic-hyperinsulinemia $(+0.4 \mathrm{~m} / \mathrm{s}$; $p=0.02$ ) but not with euglycemia, hyperglycemia, or euglycemic-hyperinsulinemia. There were no significant changes in radial artery augmentation index within any protocol (all $p>0.05$ ), though this value trended lower with hyperglycemic-hyperinsulinemia (opposite of the observed effect on carotid-femoral pulse wave velocity). No changes were observed in subendocardial viability ratio within any protocol. Heart rate significantly increased only during hyperglycemic-hyperinsulinemia $(+3.62 \mathrm{bpm} ; \mathrm{p}=0.02)$. There was a significant inverse correlation between peripheral and arterial stiffness during hyperglycemichyperinsulinemia.

Conclusions: We conclude that combined hyperglycemia and hyperinsulinemia acutely increases aortic stiffness, diminishes the normal central-to-peripheral arterial stiffness gradient, and increases heart rate in healthy humans. (ClinicalTrials.gov number NCT03520569; registered 9 May 2018).

Clinical Trial Information: ClinicalTrials.gov identifier NCT03520569 (registered 9 May 2018).

\section{Background}

Arterial stiffness develops from dynamic interactions between structural and cellular elements of the vessel wall influenced by both hemodynamic forces and extrinsic factors (including hormones, salt, and glucose) [1]. Stiffness is not uniformly distributed throughout the arterial tree but is often patchy [2, 3], occurring in central elastic and conduit muscular arteries while sparing smaller arteries $[1,4,5]$. This pattern is due to marked differences in the expression of arterial wall components when moving from central-to-peripheral vessels, with elastin predominating in central elastic arteries and collagen fibers predominating in conduit muscular arteries [6].

Increasing arterial stiffness is a physiological feature of vascular aging that is accelerated by conditions with greater cardiovascular risk, including DM [7]. Vascular aging, even in the absence of atherosclerosis, leads to intimal and medial thickening (i.e., vascular remodeling) as well as gradual loss of arterial 
elasticity [8]. Notably, arterial stiffness often antedates and is itself a strong risk factor for a spectrum of cardiovascular diseases (e.g., arterial hypertension, heart failure, myocardial infarction, etc.) [6, 7]. Data from numerous studies demonstrate that aortic stiffness (assessed by carotid-femoral pulse wave velocity (cfPWV)) is an important, independent determinant of cardiovascular risk in multiple populations [9-15] and may explain some of the notable residual cardiovascular risk associated with even wellcontrolled hypertension [16].

In healthy young adults, the central aorta is quite elastic, while peripheral, muscular arteries are inherently stiffer [6]. However, studies of the general population $[17,18]$ and hypertensive persons $[4]$ demonstrate that age-related increases in peripheral artery stiffness are less rapid than in the central arteries [6]. This differential rate of stiffening results in aortic stiffness equaling or exceeding peripheral stiffness in the majority of older individuals [6]. This change of the central-to-peripheral arterial stiffness gradient is associated with a number of adverse cardiovascular consequences, including target organ damage to heart, brain, and kidney $[6,19-21]$.

Interestingly, preferential stiffening of central over peripheral arteries occurs in type 2 DM [22-24], though mechanisms responsible for this finding are unclear. A recent editorial encouraged investigation of healthy cohorts to understand mechanisms contributing to accelerated vascular aging [25]. In this study, we sought to quantify the independent effects of elevated circulating concentrations of insulin, glucose, and both on central and peripheral arterial stiffness in healthy humans. To isolate the effects of insulin and glucose from those of incretins and autonomic changes that occur with oral glucose, we used intravenous glucose and insulin infusions with co-administration of octreotide (OCT). We measured central arterial stiffness with carotid-femoral pulse wave velocity (cfPWV), peripheral arterial stiffness with radial artery augmentation index (Al), myocardial oxygen supply and demand with subendocardial viability ratio (SEVR), and hemodynamic changes during euglycemia, hyperglycemia, euglycemichyperinsulinemia, and hyperglycemic-hyperinsulinemia.

\section{Materials And Methods}

\section{Recruitment and Study Population}

Recruitment for this study was achieved by community advertisement and direct advertisement to healthcare clinics both within and outside the University of Virginia (UVA) Health System. Healthy young adults met inclusion criteria if they were $\geq 18$ and $\leq 35$ years old, had normal body mass index (18-25 $\mathrm{kg} / \mathrm{m}^{2}$ ), did not have DM, and had fasting plasma glucose $<100 \mathrm{mg} / \mathrm{dL}$ and blood pressure $<140 / 90$ $\mathrm{mmHg}$ at time of screening. Subjects were excluded if they were current smokers or quit smoking $<5$ years ago, had a first-degree relative with type $2 \mathrm{DM}$, were taking vasoactive medications (e.g., antihypertensives, diuretics, statins, etc.), were pregnant (i.e., positive pregnancy test) or nursing, had history of allergy or prior adverse reaction to octreotide, or significant premorbid disease that could, in the investigator's opinion, affect outcome measures or subject safety. 


\section{Clinical Assessment and Initial Screening}

All screening visits and infusion studies were conducted at the UVA Clinical Research Unit (CRU). Each subject gave written informed consent at their initial visit prior to being carefully screened to verify inclusion/exclusion criteria and certify overall good health. Screening included a detailed medical history and physical examination along with fasting measures of complete blood count, comprehensive metabolic panel, lipid panel, plasma glucose, and serum pregnancy test.

\section{Experimental Protocols}

Randomization was conducted by study personnel using a 1:1:1:1 allocation with a computer-generated sequence program [26]. After randomization, study personnel were blinded to subject and protocol when evaluating outcome measures. Subjects underwent four infusion protocols (Figure 1) designed to test the effects of euglycemia, hyperglycemia, euglycemic-hyperinsulinemia, and hyperglycemic-hyperinsulinemia on arterial stiffness. All protocols were approved by the UVA Institutional Review Board (\#19948), with each protocol being performed $\geq 2$ but $\leq 4$ weeks apart for individual subjects. For each protocol, we measured cfPWV, Al, SEVR, systolic blood pressure, diastolic blood pressure, pulse pressure, mean arterial pressure, and heart rate immediately before (i.e., baseline) and at the end of the infusion period (Figure 1). Study participants were instructed to avoid alcohol, exercise, and caffeine for 24 hours and fast overnight prior to admission to the CRU. Infusion studies began with placement of intravenous catheters in the right wrist for blood sampling and in the right antecubital fossa for administration of insulin, glucose, and octreotide (OCT). Studies began with simultaneous infusion of regular insulin and OCT to maintain plasma insulin near basal levels. We did not replace glucagon or growth hormone, as there is currently no evidence that acutely suppressing basal levels of either hormone affects vascular function.

Protocol A (Euglycemia): A 90-minute saline infusion was initiated, with baseline vascular function measurements obtained during the final 30 minutes (Figure 1A). Then, OCT ( $30 \mathrm{ng} / \mathrm{kg} / \mathrm{min}$ ) with basal insulin replacement $(0.15 \mathrm{mU} / \mathrm{min} / \mathrm{kg})$ was infused for 240 minutes. Blood glucose (BG) was sampled every 10 minutes and plasma insulin every 30 minutes. Euglycemia (EU) was maintained by a variablerate glucose infusion using the negative feedback principle [27]. We then repeated vascular measurements over the final 30 minutes of study.

Protocol B (Hyperglycemia): Octreotide and basal insulin replacement were continuously infused for 90 minutes, with baseline vascular measurements obtained over the final 30 minutes (Figure 1B). Then, a primed, continuous variable-rate $20 \%$ dextrose infusion began to acutely raise and maintain BG at 200 $\mathrm{mg} / \mathrm{dL}$ using the hyperglycemic clamp method [27]. BG was sampled every 5 minutes and plasma insulin every 30 minutes, with repeat vascular measurements obtained over the final 30 minutes of hyperglycemia.

Protocol C (Euglycemic-Hyperinsulinemia): Euglycemia was maintained throughout this protocol by a variable-rate $20 \%$ dextrose infusion using the negative feedback principle [27]. Baseline arterial stiffness measurements were obtained during the final 30 minutes of an OCT (30 ng/kg/min) plus basal insulin 
$(0.15 \mathrm{mU} / \mathrm{min} / \mathrm{kg})$ infusion (Figure 1C). Then, hyperinsulinemia was initiated with a primed $(2 \mathrm{mU} / \mathrm{kg} / \mathrm{min}$ x $10 \mathrm{~min})$, continuous (1 mU/kg/min x $110 \mathrm{~min}$ ) infusion and OCT continued for 120 minutes. Blood glucose (BG) was sampled every 5 minutes and plasma insulin every 30 minutes, with repeat arterial stiffness, SEVR, and hemodynamic measurements obtained during the final 30 minutes of the insulin clamp.

Protocol D (Hyperglycemic-Hyperinsulinemia): As in Protocol C, a variable-rate $20 \%$ dextrose infusion maintained euglycemia while OCT (30 ng/ $\mathrm{kg} / \mathrm{min})$ and basal insulin $(0.15 \mathrm{mU} / \mathrm{min} / \mathrm{kg})$ were simultaneously infused for the first 90 minutes of this study (Figure 1D). Then, a primed, variable-rate $20 \%$ dextrose infusion began to acutely raise and subsequently maintain BG at $\sim 200 \mathrm{mg} / \mathrm{dL}$ using the hyperglycemic clamp method [27]. BG was then sampled every 5 minutes and plasma insulin every 30 minutes, with baseline arterial stiffness measurements obtained over the final 30 minutes of the 120minute hyperglycemic period (Figure 1B). Subsequently, hyperinsulinemia was initiated with a primed (2 $\mathrm{mU} / \mathrm{kg} / \mathrm{min} \times 10 \mathrm{~min}$ ), continuous ( $1 \mathrm{mU} / \mathrm{kg} / \mathrm{min} \times 110 \mathrm{~min}$ ) infusion with OCT and hyperglycemia maintained for 120 minutes. BG was sampled every 5 minutes with plasma insulin every 30 minutes, and repeat arterial stiffness, SEVR, and hemodynamic measurements were again obtained during the final 30 minutes of the insulin clamp.

Hemodynamics: Clinical hemodynamic assessments were obtained at two time points during each protocol (Figure 1). Blood pressure, pulse pressure, mean arterial pressure, and heart rate were measured and/or calculated with a Sphygmacor tonometer (ATCOR USA; Napierville, IL).

Carotid-Femoral Pulse Wave Velocity (cfPWV): To assess central aortic stiffness, cfPWV was measured per expert recommendations [28] using a Sphygmacor tonometer by the same trained operator. To minimize the effects of sympathetic activity on cfPWV measurements, participants laid in the supine position in a temperature-controlled room for at least 15 minutes prior to measurement. We measured the distance from the suprasternal notch to the carotid pulse and from the suprasternal notch to the femoral pulse on the same side. For each cfPWV measure, 10 seconds of carotid and 10 seconds of femoral arterial waveforms were recorded. cfPWV measures were made in duplicate and the mean value was reported. Of note, the cfPWV data in this manuscript were included in a separate report examining macroand microvascular functional responses to the two insulin clamp protocols [29].

Radial Artery Augmentation Index (Al): To assess peripheral arterial stiffness, we measured Al noninvasively with a Sphygmacor tonometer. As with cfPWV, radial Al measurements were obtained by the same trained operator after participants laid in the supine position in a temperature-controlled room for at least 15 minutes prior to measurement. Radial Al was calculated as the difference of the amplitude of the late systolic peak to the early systolic peak divided by the pulse pressure and expressed as a percentage. Radial Al values were determined for each pulse over a 30 second period and a mean value was calculated by the device for each patient and corrected for a heart rate of 75 beats per minute.

Subendocardial Viability Ratio (SEVR): Measurements used to calculate SEVR were obtained with a Sphygmacor tonometer. The area under the curve of the systolic and diastolic portions of the central 
aortic pulse wave were measured using pulse wave analysis. In the present study, the tonometric SEVR was as provided by the manufacturer; specifically, it was approximated automatically using the following equation: tonometric SEVR=diastolic aortic area/systolic aortic area [30, 31].

\section{Biochemical Analyses}

Complete blood count, comprehensive metabolic panel, lipid panel, fasting plasma glucose, and serum pregnancy tests were assayed at the UVA Clinical Chemistry Laboratory. Plasma glucose was measured with the YSI 2700 Biochemistry Analyzer (Yellow Springs Instrument Company; Yellow Springs, $\mathrm{OH}$ ). Plasma insulin was measured with the ALPCO Insulin ELISA (ALPCO; Salem, NH). Insulin assays were read on a Synergy 2 microplate reader (BioTek; Winooski, VT).

\section{Data Storage}

Study data are stored in a Research Electronic Data Capture (REDCap) [32] project file repository hosted at UVA. The datasets generated and/or analyzed during the current study are available from the corresponding author upon reasonable request.

\section{Statistical Analyses}

Sample Size: Our prior work has demonstrated that sample sizes of approximately 10-15 subjects were sufficient to identify significant within-study changes in macrovascular function under multiple metabolic conditions [33-36]. A crude sample size calculation using the Cohen's $d$ effect size from a prior study of changes in cfPWV during euglycemic-hyperinsulinemia [35] indicated that a sample size of 10 subjects would have $\geq 95 \%$ power to detect meaningful differences within each protocol.

Outcomes: The primary outcome for each protocol was change in cfPWV and secondary outcomes for each protocol included changes in Al, SEVR, systolic blood pressure, diastolic blood pressure, mean arterial pressure, pulse pressure, and plasma insulin.

Descriptive Summarization: Patient demographics were summarized using common descriptive statistics. The arithmetic mean and standard error of mean, standard deviation, median, and interquartile range were used to summarize continuous scaled outcome measures.

Statistical Analyses: Data are expressed as either mean \pm SEM or as change within protocol. Withinprotocol changes were analyzed using paired, two-tailed t-test and two sample, unequal variance t-test where appropriate. Between-protocol changes were analyzed using mixed modeling for repeated measures. Spearman's correlation was used to evaluate the relationship between cfPWV and radial Al. All statistical analyses were performed with Excel (Microsoft; Redmond, WA) and GraphPad Prism 8 (GraphPad Software; San Diego, CA). In all cases a p-value of $<0.05$ was accepted as statistically significant. 


\section{Baseline Subject Characteristics and Demographics}

Table 1 details baseline demographics of the 19 total study participants. All had normal BMI, blood pressure, and fasting plasma glucose. Notably, 13 subjects completed Protocol A, 10 subjects completed Protocol B, 14 subjects completed Protocol C, and 12 subjects completed Protocol D. Nine subjects completed all four protocols.

\section{Plasma Insulin and Glucose Concentrations}

Figure 2 shows the time course for mean plasma glucose (upper panel), mean glucose infusion rate (middle panel), and mean plasma insulin levels throughout each protocol. Plasma glucose levels rose significantly from baseline within Procotols $B$ and $D$, and plasma insulin concentrations rose significantly from baseline within Protocols $C$ and $D$. These increases did not differ between respective protocol pairs.

\section{Arterial Stiffness and Subendocardial Viability Ratio}

Figure 3 shows the boxplots for pre- and post-intervention measures of cfPWV, Al, and SEVR in each protocol. cfPWV did not change during euglycemia, hyperglycemia, or euglycemic-hyperinsulinemia (all $p>0.05)$, but significantly increased after hyperinsulinemia was added to hyperglycemia $(+0.4 \mathrm{~m} / \mathrm{s}$; $\mathrm{p}=0.02$ ) (Table 2). Radial Al trended downward within each protocol, but none of these changes reached statistical significance. Mean SEVR increased within each protocol, though none of these changes were statistically significant (all $p>0.05$ ), indicating that the balance between coronary perfusion and arterial load did not acutely change (Table 2 ).

\section{Relationship between Changes in cfPWV and Radial Al}

We noted that central and peripheral stiffness trended in opposite directions during hyperglycemichyperinsulinemia (i.e., hyperglycemic-hyperinsulinemia significantly increased cfPWV and trended towards decrease in radial $\mathrm{Al}$ ), thus we examined the relationship between change in cfPWV and change in radial Al within each protocol (Figure 4). A strong negative relationship ( $r=-0.744 ; p=0.011)$ between radial $\mathrm{Al}$ and cfPWV was identified during hyperglycemic-hyperinsulinemia, indicating that radial $\mathrm{Al}$ decreased as cfPWV increased. No relationships were identified between these variables within any other protocol.

\section{Hemodynamic Function}

Table 3 details the within-protocol changes for all hemodynamic parameters. There were no significant changes of aortic or peripheral systolic, diastolic, mean arterial, or pulse pressure within any protocol (all $p>0.05)$. However, mean arterial pressure trended towards an increase during hyperglycemichyperinsulinemia $(+4.14 \mathrm{mmHg} ; \mathrm{p}=0.09)$. Heart rate significantly increased during hyperglycemichyperinsulinemia only (+3.62 bpm; $p=0.02)$.

\section{Discussion}


To our knowledge, this study is the first to investigate the acute effects of hyperglycemia and hyperinsulinemia on central and peripheral arterial stiffness in the same subjects, with several significant and novel observations warranting discussion. First, it is the combination of both hyperglycemia and hyperinsulinemia that increases cfPWV, while isolated hyperglycemia or hyperinsulinemia alone do not. Second, hyperglycemic-hyperinsulinemia preferentially stiffens the central aorta and increases the central-to-peripheral arterial stiffness gradient, changes that are typically seen in vascular aging [6]. Finally, hyperglycemic-hyperinsulinemia acutely increases heart rate but does not alter aortic or radial systolic, diastolic, or pulse pressure.

Prior work from Puzantian et al. found that acute hyperglycemia (using pancreatic clamping methodology in healthy subjects) did not alter cfPWV, but they noted that further studies were needed to determine the independent and combined roles of glucose and insulin on cfPWV [37]. To our knowledge, the current study is the first to investigate this question. Infusion of OCT allowed us to isolate the effects of insulin and glucose and provide the first evidence that moderate hyperglycemia unmasks an action of physiologic hyperinsulinemia to increase central aortic stiffness in healthy humans. Interestingly, cfPWV increased during hyperglycemic-hyperinsulinemia without a concomitant increase in blood or pulse pressure. We note that the only variable to change during this protocol was heart rate. A positive association between heart rate and cfPWV has been demonstrated in recent studies [38, 39]. However, this effect is quite small and on the order of $0.02 \mathrm{~m} / \mathrm{s}$ per $1 \mathrm{bpm}$ change [38, 39]. Given that mean heart rate increased during hyperglycemic-hyperinsulinemia by $3.62 \mathrm{bpm}$, we would theoretically expect a $0.07 \mathrm{~m} / \mathrm{s}$ increase in mean cfPWV. Our results showed that mean cfPWV increased by $0.4 \mathrm{~m} / \mathrm{s}$ during hyperglycemic-hyperinsulinemia, indicating that increased heart rate alone cannot explain the change observed in cfPWV. This result is hypothesis-generating and raises an important question: if blood pressure and heart rate cannot fully explain the increased cfPWV, what does? We hypothesize that two unmeasured factors, namely sympathetic tone and vascular smooth muscle cell (VSMC) tone, are responsible for the observed increase in cfPWV. Norepinephrine causes vasoconstriction in most arteries and also transiently increases heart rate, resulting in increased sympathetic tone [40]. The primary source of circulating norepinephrine is spillover from sympathetic nerves innervating blood vessels, and recent work has shown that hyperglycemic-hyperinsulinemia significantly increases circulating norepinephrine (but not epinephrine) in healthy humans [41]. In contrast, insulin has vasodilatory effects, with insulinmediated vasodilation and glucose uptake being functionally linked in humans [42]. Moreover, a prior study of healthy humans utilizing the perfused forearm model demonstrated that local hyperinsulinemia caused a rightward shift of the vasoconstrictive dose-response curve to norepinephrine [43]. VSMCs are also gaining increasing attention for their role in aortic stiffness [44], with VSMC contraction and relaxation recognized as a critical regulator of aortic compliance [45]. VSMC take up and utilize norepinephrine for protein modification, and this modification plays an important role in how norepinephrine directly stimulates VSMC contraction $[46,47]$. Intriguingly, one study has shown that the combination of glucose and insulin has additive effects (beyond either factor alone) on infragenicular VSMC growth [48]. Our study was not designed to establish a mechanistic basis for how glucose, insulin, 
and potentially norepinephrine work in concert to increase aortic stiffness, but future work could focus on investigating this question.

We also found that hyperglycemic-hyperinsulinemia changes the normal central-to-peripheral arterial stiffness gradient. In healthy young individuals, the aorta is highly elastic and expands to accommodate stroke volume during systole, then recoils due to stored energy during diastole [6]. This continuous cycle of expansion and recoil is advantageous because it keeps the systolic pressure low during arterial expansion but maintains diastolic pressure during the recoil phase, allowing adequate perfusion of the coronary circulation during diastole [6]. In individuals with compliant aortas, peripheral muscular artery stiffness exceeds central elastic artery stiffness [49]. With aging, central arterial stiffness increases with little change in peripheral stiffness, resulting in a reversal of the normal stiffness gradient $[6,49]$. This decreased compliance of the central vasculature subsequently alters arterial pressure and flow dynamics and impacts cardiac performance and coronary perfusion [1]. Indeed, reversal of the normal central-toperipheral arterial stiffness gradient is associated with a number of adverse cardiovascular consequences, including transmission of excessive pressure pulsatility into the microcirculation and target organ damage [6]. Among older adults, DM is associated with greater central than peripheral arterial stiffness, with the magnitude of the effect of DM on central stiffness equating to $\sim 6$ years of arterial aging [50]. In this study, we identified an inverse relationship for change in central (cfPWV) and peripheral (radial Al) stiffness during hyperglycemic-hyperinsulinemia. Hyperglycemic-hyperinsulinemia significantly increased cfPWV and trended towards decrease in radial Al, while a significant negative correlation was identified in change of these variables (i.e., Al decreased as cfPWV increased). Our findings align with epidemiological reports demonstrating preferential stiffening of central over peripheral arteries in both T2DM [22-24,50] and T2DM with ischemic heart disease [51] (i.e., conditions characterized by hyperglycemia and hyperinsulinemia). Our prior work has also shown that insulin has opposing effects on peripheral and arterial stiffness in various metabolic conditions. Specifically, insulin (with euglycemia) acutely reduced radial Al in both healthy and metabolic syndrome subjects, but increased cfPWV in metabolic syndrome subjects only [35]. In that study, metabolic syndrome subjects were insulin-resistant and had chronically higher fasting plasma glucose and insulin concentrations (i.e., the milieu of metabolic syndrome), contributing to reversal of the normal central-to-peripheral arterial stiffness gradient during the euglycemic insulin infusion.

A third point is that hyperglycemic-hyperinsulinemia acutely increased heart rate but not central or peripheral blood pressure. Recent work has shown that arterial stiffness precedes any increase in systolic blood pressure $[52,53]$. Given the short duration of our study period, it is unsurprising that blood pressure trended up but did not significantly change. Oral glucose administration has also been shown to increase plasma norepinephrine levels [54], sympathetic nervous system activity [54, 55], and heart rate [54-56] in healthy humans. Acute hyperglycemia [57] and norepinephrine [58] are established inducers of insulin resistance, and epidemiological studies indicate that insulin resistance is associated with higher resting heart rate in healthy populations $[59,60]$. Thus, the increase in heart rate seen during hyperglycemichyperinsulinemia in this study mimics the increased sympathetic nervous system activity observed in metabolic syndrome [61]. 
Taken together, our findings suggest a potential mechanism for how DM increases aortic stiffness, alters the normal central-to-peripheral arterial stiffness gradient, and ultimately contributes to the development of cardiovascular disease. Preclinical studies of human aortic endothelial cells have shown that both insulin [62] and hyperglycemia [63] independently increase expression of endothelial nitric oxide synthase and production of nitric oxide, while hyperglycemia in the presence of insulin specifically inhibits insulinstimulated nitric oxide synthesis and downregulates some aspects of insulin signaling (including the Akt and CAP/Cbl signaling pathways) $[57,64,65]$. Insulin, at physiological concentrations, has acute vasodilatory effects that increase arterial (especially aortic) distensibility; however, these beneficial effects are blunted in insulin-resistant states characterized by hyperglycemia (including obesity, metabolic syndrome, and types 1 and 2 DM $[66,67])$. Srinivasan et al. studied 20 persons with type 1 DM during either euglycemic-hyperinsulinemia or hyperglycemic-hyperinsulinemia and found that acute hyperglycemia has a deleterious effect on myocardial vasodilator function that outweighs the beneficial effects of hyperinsulinemia [68]. Insulin resistance in type 2 DM has been shown to limit insulin's ability to decrease central aortic pressure, which may predispose to development of systolic hypertension [69]. Similarly, Henry et al. reported a greater impact of type 2 DM on central arteries, emphasizing that the increase in arterial stiffness begins from the stage of impaired glucose tolerance, with underlying mechanisms including hyperglycemia and glucotoxicity, advanced glycation end products, hyperinsulinemia and insulin resistance, endothelial dysfunction, and oxidative stress ultimately leading to arterial wall remodeling [70]. In the current study, we build upon these findings and note that acute hyperglycemic-hyperinsulinemia (for merely two hours in lean, healthy subjects) increases central aortic stiffness and heart rate when compared to euglycemia, hyperglycemia, and euglycemic-hyperinsulinemia. These results have implications for future research given that the phenotype of type 2 DM includes both hyperglycemia and hyperinsulinemia, and that persons with type $1 \mathrm{DM}$ experience frequent and wide hyperglycemic excursions in the setting of hyperinsulinemia due to mismatched timing of insulin administration and meal intake.

There are several limitations to the current study. First, we studied a small number of healthy young adults and the study was powered to detect within-protocol responses to glucose and insulin. Thus, we identified no between-protocol response differences, likely due to insufficient statistical power. Second, persons with DM or those who are older and/or less healthy might respond differently. Finally, we cannot rule out that OCT has in some unknown manner skewed the vascular responses and recognize that this possibility cannot be discounted. We do note, however, that no vasoactive effects have been identified in previous studies using a similar dose of OCT $[41,71-73]$ and that OCT infusion does not alter the hemodynamic effects of acute hyperglycemia [74].

\section{Conclusions}

We conclude that the combination of hyperglycemia with hyperinsulinemia increases aortic stiffness, changes the normal central-to-peripheral arterial stiffness gradient, and increases heart rate in healthy humans. These changes, if sustained chronically, may contribute to the development of cardiovascular disease. 


\section{Abbreviations}

cfPWV = carotid-femoral pulse wave velocity; $\mathrm{DM}=$ diabetes mellitus; $\mathrm{OCT}$ = octreotide; $\mathrm{Al}=$ augmentation index; $\mathrm{SEVR}$ = subendocardial viability ratio; UVA = University of Virginia; $\mathrm{CRU}$ = clinical research unit; $\mathrm{BG}=$ blood glucose; VSMC = vascular smooth muscle cell.

\section{Declarations}

Ethics Approval and Consent to Participate: All protocols were approved by the University of Virginia Institutional Review Board (\#19948). Each subject gave written informed consent at their initial screening visit prior to study participation.

Consent for Publication: Not Applicable

Availability of Data and Materials: The datasets used and/or analyzed during the current study are available from the corresponding author on reasonable request.

Competing Interests: The authors declare that they have no competing interests.

Funding: This work was supported in part by NIH research grants F32HL14230401, KL2TR003016, and UL1TR003015 (to WBH) and R01DK073059 and R01HL142250 (to EJB).

Author Contributions: WBH and EJB conceived and designed the study. WBH, LAJ, LMH, KWA, JTP, and EJB acquired, analyzed, and interpreted data. WBH drafted the manuscript. WBH, LAJ, LMH, KWA, JTP, and EJB revised the manuscript. All authors approved the final version of the manuscript before submission.

Acknowledgements: Not Applicable

Authors' Information: Not Applicable

\section{References}

1. Zieman SJ, Melenovsky V, Kass DA: Mechanisms, pathophysiology, and therapy of arterial stiffness. Arterioscler Thromb Vasc Biol 2005, 25(5):932-943.

2. Galis ZS, Khatri JJ: Matrix metalloproteinases in vascular remodeling and atherogenesis: the good, the bad, and the ugly. Circ Res 2002, 90(3):251-262.

3. Bassiouny HS, Zarins CK, Kadowaki MH, Glagov S: Hemodynamic stress and experimental aortoiliac atherosclerosis. J Vasc Surg 1994, 19(3):426-434.

4. Benetos A, Laurent S, Hoeks AP, Boutouyrie PH, Safar ME: Arterial alterations with aging and high blood pressure. A noninvasive study of carotid and femoral arteries. Arterioscler Thromb 1993, 13(1):90-97. 
5. Gillessen T, Gillessen F, Sieberth H, Hanrath P, Heintz B: Age-related changes in the elastic properties of the aortic tree in normotensive patients: investigation by intravascular ultrasound. Eur $\mathrm{J}$ Med Res 1995, 1(3):144-148.

6. Yu S, McEniery CM: Central Versus Peripheral Artery Stiffening and Cardiovascular Risk. Arterioscler Thromb Vasc Biol 2020, 40(5):1028-1033.

7. Lyle AN, Raaz U: Killing Me Unsoftly: Causes and Mechanisms of Arterial Stiffness. Arterioscler Thromb Vasc Biol 2017, 37(2):e1-e11.

8. Bolton E, Rajkumar C: The ageing cardiovascular system. Reviews in Clinical Gerontology 2011, 21(2):99-109.

9. Boutouyrie P, Tropeano Al, Asmar R, Gautier I, Benetos A, Lacolley P, Laurent S: Aortic stiffness is an independent predictor of primary coronary events in hypertensive patients: a longitudinal study. Hypertension 2002, 39(1):10-15.

10. Laurent S, Boutouyrie P, Asmar R, Gautier I, Laloux B, Guize L, Ducimetiere P, Benetos A: Aortic stiffness is an independent predictor of all-cause and cardiovascular mortality in hypertensive patients. Hypertension 2001, 37(5):1236-1241.

11. Ben-Shlomo Y, Spears M, Boustred C, May M, Anderson SG, Benjamin EJ, Boutouyrie P, Cameron J, Chen $\mathrm{CH}$, Cruickshank JK et al: Aortic pulse wave velocity improves cardiovascular event prediction: an individual participant meta-analysis of prospective observational data from 17,635 subjects. $J$ Am Coll Cardiol 2014, 63(7):636-646.

12. London GM, Blacher J, Pannier B, Guerin AP, Marchais SJ, Safar ME: Arterial wave reflections and survival in end-stage renal failure. Hypertension 2001, 38(3):434-438.

13. Cruickshank K, Riste L, Anderson SG, Wright JS, Dunn G, Gosling RG: Aortic pulse-wave velocity and its relationship to mortality in diabetes and glucose intolerance: an integrated index of vascular function? Circulation 2002, 106(16):2085-2090.

14. Sutton-Tyrrell K, Najjar SS, Boudreau RM, Venkitachalam L, Kupelian V, Simonsick EM, Havlik R, Lakatta EG, Spurgeon $\mathrm{H}$, Kritchevsky $\mathrm{S}$ et al: Elevated aortic pulse wave velocity, a marker of arterial stiffness, predicts cardiovascular events in well-functioning older adults. Circulation 2005, 111(25):3384-3390.

15. Mitchell GF, Hwang SJ, Vasan RS, Larson MG, Pencina MJ, Hamburg NM, Vita JA, Levy D, Benjamin EJ: Arterial stiffness and cardiovascular events: the Framingham Heart Study. Circulation 2010, 121(4):505-511.

16. Niiranen TJ, Kalesan B, Hamburg NM, Benjamin EJ, Mitchell GF, Vasan RS: Relative Contributions of Arterial Stiffness and Hypertension to Cardiovascular Disease: The Framingham Heart Study. J Am Heart Assoc 2016, 5(11).

17. Mitchell GF, Parise H, Benjamin EJ, Larson MG, Keyes MJ, Vita JA, Vasan RS, Levy D: Changes in arterial stiffness and wave reflection with advancing age in healthy men and women: the Framingham Heart Study. Hypertension 2004, 43(6):1239-1245. 
18. McEniery CM, Yasmin, Hall IR, Qasem A, Wilkinson IB, Cockcroft JR, Investigators A: Normal vascular aging: differential effects on wave reflection and aortic pulse wave velocity: the Anglo-Cardiff Collaborative Trial (ACCT). J Am Coll Cardiol 2005, 46(9):1753-1760.

19. Lu Y, Zhu M, Bai B, Chi C, Yu S, Teliewubai J, Xu H, Wang K, Xiong J, Zhou Y et al: Comparison of Carotid-Femoral and Brachial-Ankle Pulse-Wave Velocity in Association With Target Organ Damage in the Community-Dwelling Elderly Chinese: The Northern Shanghai Study. J Am Heart Assoc 2017, 6(2).

20. Mitchell GF: Aortic stiffness, pressure and flow pulsatility, and target organ damage. J App/ Physiol (1985) 2018, 125(6):1871-1880.

21. Vasan RS, Short MI, Niiranen TJ, Xanthakis V, DeCarli C, Cheng S, Seshadri S, Mitchell GF: Interrelations Between Arterial Stiffness, Target Organ Damage, and Cardiovascular Disease Outcomes. J Am Heart Assoc 2019, 8(14):e012141.

22. Cardoso CR, Ferreira MT, Leite NC, Barros PN, Conte PH, Salles GF: Microvascular degenerative complications are associated with increased aortic stiffness in type 2 diabetic patients. Atherosclerosis 2009, 205(2):472-476.

23. Kimoto E, Shoji T, Shinohara K, Inaba M, Okuno Y, Miki T, Koyama H, Emoto M, Nishizawa Y: Preferential stiffening of central over peripheral arteries in type 2 diabetes. Diabetes 2003, 52(2):448452.

24. Kimoto E, Shoji T, Shinohara K, Hatsuda S, Mori K, Fukumoto S, Koyama H, Emoto M, Okuno Y, Nishizawa $Y$ : Regional arterial stiffness in patients with type 2 diabetes and chronic kidney disease. J Am Soc Nephrol 2006, 17(8):2245-2252.

25. Currie G, Delles C: Healthy Vascular Aging. Hypertension 2017, 70(2):229-231.

26. Research Randomizer (Version 4.0) [http://www.randomizer.org/ ]

27. DeFronzo RA, Tobin JD, Andres R: Glucose clamp technique: a method for quantifying insulin secretion and resistance. Am J Physio/ 1979, 237(3):E214-223.

28. Townsend RR, Wilkinson IB, Schiffrin EL, Avolio AP, Chirinos JA, Cockcroft JR, Heffernan KS, Lakatta EG, McEniery CM, Mitchell GF et al: Recommendations for Improving and Standardizing Vascular Research on Arterial Stiffness: A Scientific Statement From the American Heart Association. Hypertension 2015, 66(3):698-722.

29. Horton WB, Jahn LA, Hartline LM, Aylor KW, Patrie JT, Barrett EJ: Hyperglycemia does not Inhibit Insulin's Effects on Microvascular Perfusion in Healthy Humans: A Randomized Crossover Study. Am J Physiol Endocrinol Metab 2020.

30. Tsiachris D, Tsioufis C, Syrseloudis D, Roussos D, Tatsis I, Dimitriadis K, Toutouzas K, Tsiamis E, Stefanadis C: Subendocardial viability ratio as an index of impaired coronary flow reserve in hypertensives without significant coronary artery stenoses. J Hum Hypertens 2012, 26(1):64-70.

31. Nichols WW, O'Rourke MF, McDonald DA: McDonald's blood flow in arteries : theoretic, experimental, and clinical principles. London; New York: Hodder Arnold ; Distributed in the U.S.A. by Oxford University Press; 2005. 
32. Harris PA, Taylor R, Minor BL, Elliott V, Fernandez M, O'Neal L, McLeod L, Delacqua G, Delacqua F, Kirby $\mathrm{J}$ et al: The REDCap consortium: Building an international community of software platform partners. J Biomed Inform 2019, 95:103208.

33. Chai W, Liu J, Jahn LA, Fowler DE, Barrett EJ, Liu Z: Salsalate attenuates free fatty acid-induced microvascular and metabolic insulin resistance in humans. Diabetes Care 2011, 34(7):1634-1638.

34. Eggleston EM, Jahn LA, Barrett EJ: Hyperinsulinemia rapidly increases human muscle microvascular perfusion but fails to increase muscle insulin clearance: evidence that a saturable process mediates muscle insulin uptake. Diabetes 2007, 56(12):2958-2963.

35. Jahn LA, Hartline L, Rao N, Logan B, Kim JJ, Aylor K, Gan LM, Westergren HU, Barrett EJ: Insulin Enhances Endothelial Function Throughout the Arterial Tree in Healthy But Not Metabolic Syndrome Subjects. J Clin Endocrinol Metab 2016, 101(3):1198-1206.

36. Wang N, Tan AWK, Jahn LA, Hartline L, Patrie JT, Lin S, Barrett EJ, Aylor KW, Liu Z: Vasodilatory Actions of Glucagon-Like Peptide 1 Are Preserved in Skeletal and Cardiac Muscle Microvasculature but Not in Conduit Artery in Obese Humans With Vascular Insulin Resistance. Diabetes Care 2020, 43(3):634-642.

37. Puzantian H, Teff K, Townsend RR: Investigating the effect of glucose on aortic pulse wave velocity using pancreatic clamping methodology. Biol Res Nurs 2015, 17(3):270-275.

38. Logan JG, Kim SS: Resting Heart Rate and Aortic Stiffness in Normotensive Adults. Korean Circ J 2016, 46(6):834-840.

39. Tan I, Spronck B, Kiat H, Barin E, Reesink KD, Delhaas T, Avolio AP, Butlin M: Heart Rate Dependency of Large Artery Stiffness. Hypertension 2016, 68(1):236-242.

40. Gordan R, Gwathmey JK, Xie LH: Autonomic and endocrine control of cardiovascular function. World J Cardio/ 2015, 7(4):204-214.

41. Joy NG, Perkins JM, Mikeladze M, Younk L, Tate DB, Davis SN: Comparative effects of acute hypoglycemia and hyperglycemia on pro-atherothrombotic biomarkers and endothelial function in non-diabetic humans. J Diabetes Complications 2016, 30(7):1275-1281.

42. Cleland SJ, Petrie JR, Ueda S, Elliott HL, Connell JM: Insulin-mediated vasodilation and glucose uptake are functionally linked in humans. Hypertension 1999, 33(1 Pt 2):554-558.

43. Jern S: Effects of insulin on vascular responses to mental stress and norepinephrine in human forearm. Hypertension 1994, 24(6):686-694.

44. Sehgel NL, Zhu Y, Sun Z, Trzeciakowski JP, Hong Z, Hunter WC, Vatner DE, Meininger GA, Vatner SF: Increased vascular smooth muscle cell stiffness: a novel mechanism for aortic stiffness in hypertension. Am J Physiol Heart Circ Physiol 2013, 305(9):H1281-1287.

45. Leloup AJA, Van Hove CE, De Moudt S, De Meyer GRY, De Keulenaer GW, Fransen P: Vascular smooth muscle cell contraction and relaxation in the isolated aorta: a critical regulator of large artery compliance. Physiol Rep 2019, 7(4):e13934.

46. Touyz RM, Alves-Lopes R, Rios FJ, Camargo LL, Anagnostopoulou A, Arner A, Montezano AC: Vascular smooth muscle contraction in hypertension. Cardiovasc Res 2018, 114(4):529-539. 
47. Johnson $\mathrm{KB}$, Thompson JM, Watts SW: Modification of proteins by norepinephrine is important for vascular contraction. Front Physiol 2010, 1:131.

48. Avena R, Mitchell ME, Neville RF, Sidawy AN: The additive effects of glucose and insulin on the proliferation of infragenicular vascular smooth muscle cells. J Vasc Surg 1998, 28(6):1033-1038; discussion 1038-1039.

49. Hickson SS, Nichols WW, Yasmin, McDonnell BJ, Cockcroft JR, Wilkinson IB, McEniery CM: Influence of the central-to-peripheral arterial stiffness gradient on the timing and amplitude of wave reflections. Hypertens Res 2016, 39(10):723-729.

50. Loehr LR, Meyer ML, Poon AK, Selvin E, Palta P, Tanaka H, Pankow JS, Wright JD, Griswold ME, Wagenknecht LE et al: Prediabetes and Diabetes Are Associated With Arterial Stiffness in Older Adults: The ARIC Study. Am J Hypertens 2016, 29(9):1038-1045.

51. Hatsuda S, Shoji T, Shinohara K, Kimoto E, Mori K, Fukumoto S, Koyama H, Emoto M, Nishizawa Y: Regional arterial stiffness associated with ischemic heart disease in type 2 diabetes mellitus. $J$ Atheroscler Thromb 2006, 13(2):114-121.

52. Kaess BM, Rong J, Larson MG, Hamburg NM, Vita JA, Levy D, Benjamin EJ, Vasan RS, Mitchell GF: Aortic stiffness, blood pressure progression, and incident hypertension. JAMA 2012, 308(9):875-881.

53. Weisbrod RM, Shiang T, Al Sayah L, Fry JL, Bajpai S, Reinhart-King CA, Lob HE, Santhanam L, Mitchell G, Cohen RA et al: Arterial stiffening precedes systolic hypertension in diet-induced obesity. Hypertension 2013, 62(6):1105-1110.

54. Hegedus L, Christensen NJ, Sestoft L: Abnormal regulation of sympathetic nervous activity and heart rate after oral glucose in type 1 (insulin-dependent) diabetic patients. Diabetologia 1983, 25(3):242246.

55. Synowski SJ, Kop WJ, Warwick ZS, Waldstein SR: Effects of glucose ingestion on autonomic and cardiovascular measures during rest and mental challenge. J Psychosom Res 2013, 74(2):149-154.

56. Russell RD, Hu D, Greenaway T, Sharman JE, Rattigan S, Richards SM, Keske MA: Oral glucose challenge impairs skeletal muscle microvascular blood flow in healthy people. Am J Physiol Endocrinol Metab 2018, 315(2):E307-E315.

57. Tomas E, Lin YS, Dagher Z, Saha A, Luo Z, Ido Y, Ruderman NB: Hyperglycemia and insulin resistance: possible mechanisms. Ann NY Acad Sci 2002, 967:43-51.

58. Khoury N, McGill JB: Reduction in insulin sensitivity following administration of the clinically used low-dose pressor, norepinephrine. Diabetes Metab Res Rev 2011, 27(6):604-608.

59. Moan A, Nordby G, Os I, Birkeland KI, Kjeldsen SE: Relationship between hemorrheologic factors and insulin sensitivity in healthy young men. Metabolism 1994, 43(4):423-427.

60. Stern MP, Morales PA, Haffner SM, Valdez RA: Hyperdynamic circulation and the insulin resistance syndrome ("syndrome X"). Hypertension 1992, 20(6):802-808.

61. Moreira MC, Pinto IS, Mourao AA, Fajemiroye JO, Colombari E, Reis AA, Freiria-Oliveira AH, FerreiraNeto ML, Pedrino GR: Does the sympathetic nervous system contribute to the pathophysiology of metabolic syndrome? Front Physiol 2015, 6:234. 
62. Aljada A, Dandona P: Effect of insulin on human aortic endothelial nitric oxide synthase. Metabolism 2000, 49(2):147-150.

63. Cosentino F, Hishikawa K, Katusic ZS, Luscher TF: High glucose increases nitric oxide synthase expression and superoxide anion generation in human aortic endothelial cells. Circulation 1997, 96(1):25-28.

64. Salt IP, Morrow VA, Brandie FM, Connell JM, Petrie JR: High glucose inhibits insulin-stimulated nitric oxide production without reducing endothelial nitric-oxide synthase Ser1177 phosphorylation in human aortic endothelial cells. J Biol Chem 2003, 278(21):18791-18797.

65. Luo Z, Fujio Y, Kureishi Y, Rudic RD, Daumerie G, Fulton D, Sessa WC, Walsh K: Acute modulation of endothelial Akt/PKB activity alters nitric oxide-dependent vasomotor activity in vivo. J Clin Invest 2000, 106(4):493-499.

66. Yki-Jarvinen $\mathrm{H}$, Westerbacka J: Insulin resistance, arterial stiffness and wave reflection. Adv Cardiol 2007, 44:252-260.

67. Stehouwer CD, Henry RM, Ferreira I: Arterial stiffness in diabetes and the metabolic syndrome: a pathway to cardiovascular disease. Diabetologia 2008, 51(4):527-539.

68. Srinivasan M, Herrero P, McGill JB, Bennik J, Heere B, Lesniak D, Davila-Roman VG, Gropler RJ: The effects of plasma insulin and glucose on myocardial blood flow in patients with type 1 diabetes mellitus. J Am Coll Cardio/ 2005, 46(1):42-48.

69. Tamminen M, Westerbacka J, Vehkavaara S, Yki-Jarvinen H: Insulin-induced decreases in aortic wave reflection and central systolic pressure are impaired in type 2 diabetes. Diabetes Care 2002, 25(12):2314-2319.

70. Henry RM, Kostense PJ, Spijkerman AM, Dekker JM, Nijpels G, Heine RJ, Kamp O, Westerhof N, Bouter LM, Stehouwer CD et al: Arterial stiffness increases with deteriorating glucose tolerance status: the Hoorn Study. Circulation 2003, 107(16):2089-2095.

71. Beckman JA, Goldfine AB, Gordon MB, Creager MA: Ascorbate restores endothelium-dependent vasodilation impaired by acute hyperglycemia in humans. Circulation 2001, 103(12):1618-1623.

72. Beckman JA, Goldfine AB, Gordon MB, Garrett LA, Creager MA: Inhibition of protein kinase Cbeta prevents impaired endothelium-dependent vasodilation caused by hyperglycemia in humans. Circ Res 2002, 90(1):107-111.

73. Moller N, Bagger JP, Schmitz O, Jorgensen JO, Ovesen P, Moller J, Alberti KG, Orskov H: Somatostatin enhances insulin-stimulated glucose uptake in the perfused human forearm. J Clin Endocrinol Metab 1995, 80(6):1789-1793.

74. Marfella R, Nappo F, De Angelis L, Paolisso G, Tagliamonte MR, Giugliano D: Hemodynamic effects of acute hyperglycemia in type 2 diabetic patients. Diabetes Care 2000, 23(5):658-663.

\section{Tables}


Table 1

Baseline Subject Characteristics and Demographics.

\begin{tabular}{|ll|}
\hline Variable & Mean \pm SEM \\
\hline Sex & 12 Female; 7 Male \\
\hline Age (years) & $24.4 \pm 1.0$ \\
\hline Body Mass Index $\left(\mathrm{kg} / \mathrm{m}^{2}\right)$ & $22.4 \pm 0.4$ \\
\hline Systolic Blood Pressure $(\mathrm{mmHg})$ & $114.9 \pm 2.6$ \\
\hline Diastolic Blood Pressure $(\mathrm{mmHg})$ & $66.5 \pm 1.9$ \\
\hline Fasting Blood Glucose $(\mathrm{mg} / \mathrm{dL})$ & $87.8 \pm 1.4$ \\
\hline Total Cholesterol $(\mathrm{mg} / \mathrm{dL})$ & $162.4 \pm 5.4$ \\
\hline LDL Cholesterol (mg/dL) & $92.1 \pm 5.1$ \\
\hline HDL Cholesterol $(\mathrm{mg} / \mathrm{dL})$ & $59.9 \pm 2.9$ \\
\hline Triglycerides $(\mathrm{mg} / \mathrm{dL})$ & $63.6 \pm 5.0$ \\
\hline SEM = standard error of mean & \\
\hline
\end{tabular}

Table 2. Summary statistics for pre- and post-intervention cfPWV, radial Al, and SEVR. (cfPWV= carotidfemoral pulse wave velocity; $\mathrm{Al}=$ augmentation index; $\mathrm{SEVR}=$ subendocarial viability ratio; $\mathrm{EG}=$ euglycemia; $\mathrm{HG}=$ hyperglycemia; $\mathrm{EH}=$ euglycemic-hyperinsulinemia; $\mathrm{HH}=$ hyperglycemichyperinsulinemia; $\mathrm{SEM}=$ standard error of mean). 


\begin{tabular}{|c|c|c|c|c|c|}
\hline Vascular Parameter & Protocol & Assessment & $\mathrm{n}$ & Mean \pm SEM & P-value \\
\hline \multirow[t]{8}{*}{ cfPWV } & \multirow[t]{2}{*}{ EG } & Pre & 13 & $5.25 \pm 0.13$ & \multirow[t]{2}{*}{0.74} \\
\hline & & Post & 13 & $5.21 \pm 0.18$ & \\
\hline & \multirow[t]{2}{*}{$H G$} & Pre & 10 & $4.91 \pm 0.23$ & \multirow[t]{2}{*}{0.88} \\
\hline & & Post & 10 & $4.79 \pm 0.26$ & \\
\hline & \multirow[t]{2}{*}{$\mathrm{EH}$} & Pre & 14 & $5.19 \pm 0.25$ & \multirow[t]{2}{*}{0.40} \\
\hline & & Post & 14 & $5.06 \pm 0.20$ & \\
\hline & \multirow[t]{2}{*}{$\mathrm{HH}$} & Pre & 12 & $4.67 \pm 0.12$ & \multirow[t]{2}{*}{0.02} \\
\hline & & Post & 12 & $5.07 \pm 0.20$ & \\
\hline \multirow[t]{8}{*}{ Radial Al } & \multirow[t]{2}{*}{ EG } & Pre & 13 & $0.08 \pm 3.56$ & \multirow[t]{2}{*}{0.07} \\
\hline & & Post & 13 & $-4.15 \pm 3.25$ & \\
\hline & \multirow[t]{2}{*}{$H G$} & Pre & 10 & $-2.80 \pm 4.22$ & \multirow[t]{2}{*}{0.13} \\
\hline & & Post & 10 & $-4.80 \pm 3.83$ & \\
\hline & \multirow[t]{2}{*}{$\mathrm{EH}$} & Pre & 14 & $-0.79 \pm 2.37$ & \multirow[t]{2}{*}{0.10} \\
\hline & & Post & 14 & $-2.23 \pm 3.27$ & \\
\hline & \multirow[t]{2}{*}{$\mathrm{HH}$} & Pre & 12 & $-4.25 \pm 2.67$ & \multirow[t]{2}{*}{0.12} \\
\hline & & Post & 12 & $-8.45 \pm 2.76$ & \\
\hline \multirow[t]{8}{*}{ SEVR } & \multirow[t]{2}{*}{ EG } & Pre & 13 & $167.77 \pm 9.76$ & \multirow[t]{2}{*}{0.09} \\
\hline & & Post & 13 & $178.92 \pm 9.98$ & \\
\hline & \multirow[t]{2}{*}{$H G$} & Pre & 10 & $195.60 \pm 12.80$ & \multirow[t]{2}{*}{0.51} \\
\hline & & Post & 10 & $201.90 \pm 9.97$ & \\
\hline & \multirow[t]{2}{*}{$\mathrm{EH}$} & Pre & 13 & $184.00 \pm 9.53$ & \multirow[t]{2}{*}{0.40} \\
\hline & & Post & 13 & $194.15 \pm 11.75$ & \\
\hline & \multirow[t]{2}{*}{$\mathrm{HH}$} & Pre & 12 & $173.08 \pm 6.85$ & \multirow[t]{2}{*}{0.64} \\
\hline & & Post & 12 & $183.18 \pm 16.19$ & \\
\hline
\end{tabular}

Table 3. Summary statistics for pre- and post-intervention hemodynamic parameters. (sBP= systolic blood pressure; $\mathrm{dBP}=$ diastolic blood pressure; $\mathrm{PP}=$ pulse pressure; $\mathrm{MAP}=$ mean arterial pressure; $\mathrm{HR}=$ heart rate; $\mathrm{EG}=$ euglycemia; $\mathrm{HG}=$ hyperglycemia; $\mathrm{EH}=$ euglycemic-hyperinsulinemia; $\mathrm{HH}=$ hyperglycemichyperinsulinemia; SEM= standard error of mean). 


\begin{tabular}{|c|c|c|c|c|c|}
\hline Hemodynamic Parameter & Protocol & Assessment & $\mathrm{n}$ & Mean \pm SEM & P-value \\
\hline \multirow[t]{8}{*}{ Central sBP } & \multirow[t]{2}{*}{ EG } & Pre & 13 & $95.54 \pm 2.27$ & \multirow[t]{2}{*}{0.72} \\
\hline & & Post & 13 & $95.00 \pm 2.66$ & \\
\hline & \multirow[t]{2}{*}{ HG } & Pre & 10 & $95.20 \pm 3.57$ & \multirow[t]{2}{*}{0.40} \\
\hline & & Post & 10 & $93.80 \pm 2.99$ & \\
\hline & \multirow[t]{2}{*}{$\mathrm{EH}$} & Pre & 14 & $96.43 \pm 3.11$ & \multirow[t]{2}{*}{0.35} \\
\hline & & Post & 14 & $98.57 \pm 2.13$ & \\
\hline & \multirow[t]{2}{*}{$\mathrm{HH}$} & Pre & 12 & $92.75 \pm 2.95$ & \multirow[t]{2}{*}{0.33} \\
\hline & & Post & 12 & $95.64 \pm 2.48$ & \\
\hline \multirow[t]{8}{*}{ Central dBP } & \multirow[t]{2}{*}{ EG } & Pre & 13 & $66.23 \pm 1.90$ & \multirow[t]{2}{*}{0.25} \\
\hline & & Post & 13 & $67.69 \pm 1.98$ & \\
\hline & \multirow[t]{2}{*}{$H G$} & Pre & 10 & $66.10 \pm 2.63$ & \multirow[t]{2}{*}{0.42} \\
\hline & & Post & 10 & $64.40 \pm 2.55$ & \\
\hline & \multirow[t]{2}{*}{$\mathrm{EH}$} & Pre & 14 & $67.29 \pm 3.06$ & \multirow[t]{2}{*}{0.13} \\
\hline & & Post & 14 & $70.29 \pm 2.31$ & \\
\hline & \multirow[t]{2}{*}{$\mathrm{HH}$} & Pre & 12 & $61.75 \pm 3.39$ & \multirow[t]{2}{*}{0.10} \\
\hline & & Post & 12 & $65.91 \pm 2.62$ & \\
\hline \multirow[t]{8}{*}{ Central PP } & \multirow[t]{2}{*}{ EG } & Pre & 13 & $30.00 \pm 1.56$ & \multirow[t]{2}{*}{0.09} \\
\hline & & Post & 13 & $27.31 \pm 1.19$ & \\
\hline & \multirow[t]{2}{*}{$\mathrm{HG}$} & Pre & 10 & $29.10 \pm 1.54$ & \multirow[t]{2}{*}{0.81} \\
\hline & & Post & 10 & $29.40 \pm 1.84$ & \\
\hline & \multirow[t]{2}{*}{$\mathrm{EH}$} & Pre & 13 & $29.14 \pm 1.83$ & \multirow[t]{2}{*}{0.70} \\
\hline & & Post & 13 & $28.29 \pm 1.55$ & \\
\hline & \multirow[t]{2}{*}{$\mathrm{HH}$} & Pre & 12 & $31.00 \pm 1.50$ & \multirow[t]{2}{*}{0.38} \\
\hline & & Post & 12 & $29.73 \pm 1.36$ & \\
\hline
\end{tabular}




\begin{tabular}{|c|c|c|c|c|c|}
\hline \multirow[t]{8}{*}{ MAP } & \multirow[t]{2}{*}{ EG } & Pre & 13 & $79.85 \pm 1.89$ & \multirow[t]{2}{*}{0.71} \\
\hline & & Post & 13 & $80.31 \pm 2.13$ & \\
\hline & \multirow[t]{2}{*}{ HG } & Pre & 10 & $78.90 \pm 2.92$ & \multirow[t]{2}{*}{0.35} \\
\hline & & Post & 10 & $77.30 \pm 2.74$ & \\
\hline & \multirow[t]{2}{*}{$\mathrm{EH}$} & Pre & 14 & $80.50 \pm 3.00$ & \multirow[t]{2}{*}{0.14} \\
\hline & & Post & 14 & $83.21 \pm 2.23$ & \\
\hline & \multirow[t]{2}{*}{$\mathrm{HH}$} & Pre & 12 & $75.50 \pm 3.19$ & \multirow[t]{2}{*}{0.10} \\
\hline & & Post & 12 & $79.64 \pm 2.52$ & \\
\hline \multirow[t]{8}{*}{ Peripheral sBP } & \multirow[t]{2}{*}{ EG } & Pre & 13 & $110.15 \pm 2.54$ & \multirow[t]{2}{*}{0.53} \\
\hline & & Post & 13 & $111.23 \pm 3.13$ & \\
\hline & \multirow[t]{2}{*}{ HG } & Pre & 10 & $110.10 \pm 3.77$ & \multirow[t]{2}{*}{0.66} \\
\hline & & Post & 10 & $110.80 \pm 3.58$ & \\
\hline & \multirow[t]{2}{*}{$\mathrm{EH}$} & Pre & 14 & $111.86 \pm 2.96$ & \multirow[t]{2}{*}{0.13} \\
\hline & & Post & 14 & $116.00 \pm 2.52$ & \\
\hline & \multirow[t]{2}{*}{$\mathrm{HH}$} & Pre & 12 & $110.25 \pm 2.83$ & \multirow[t]{2}{*}{0.22} \\
\hline & & Post & 12 & $114.27 \pm 2.80$ & \\
\hline \multirow[t]{8}{*}{ Peripheral dBP } & \multirow[t]{2}{*}{ EG } & Pre & 13 & $65.62 \pm 1.89$ & \multirow[t]{2}{*}{0.35} \\
\hline & & Post & 13 & $66.85 \pm 2.02$ & \\
\hline & \multirow[t]{2}{*}{ HG } & Pre & 10 & $65.40 \pm 2.60$ & \multirow[t]{2}{*}{0.44} \\
\hline & & Post & 10 & $63.70 \pm 2.52$ & \\
\hline & \multirow[t]{2}{*}{$\mathrm{EH}$} & Pre & 14 & $66.36 \pm 2.96$ & \multirow[t]{2}{*}{0.13} \\
\hline & & Post & 14 & $69.29 \pm 2.20$ & \\
\hline & \multirow[t]{2}{*}{$\mathrm{HH}$} & Pre & 12 & $61.00 \pm 3.34$ & \multirow[t]{2}{*}{0.11} \\
\hline & & Post & 12 & $65.09 \pm 2.67$ & \\
\hline
\end{tabular}




\section{Figures}

\begin{tabular}{|c|c|c|c|c|c|}
\hline \multirow[t]{8}{*}{ Peripheral PP } & \multirow[t]{2}{*}{ EG } & Pre & 13 & $46.46 \pm 2.16$ & \multirow[t]{2}{*}{1.00} \\
\hline & & Post & 13 & $46.46 \pm 2.42$ & \\
\hline & \multirow[t]{2}{*}{ HG } & Pre & 10 & $44.70 \pm 2.09$ & \multirow[t]{2}{*}{0.25} \\
\hline & & Post & 10 & $47.10 \pm 2.76$ & \\
\hline & \multirow[t]{2}{*}{$\mathrm{EH}$} & Pre & 14 & $45.50 \pm 2.18$ & \multirow[t]{2}{*}{0.55} \\
\hline & & Post & 14 & $47.43 \pm 2.64$ & \\
\hline & \multirow[t]{2}{*}{$\mathrm{HH}$} & Pre & 12 & $49.25 \pm 1.73$ & \multirow[t]{2}{*}{0.53} \\
\hline & & Post & 12 & $47.55 \pm 3.10$ & \\
\hline \multirow[t]{8}{*}{ HR } & \multirow[t]{2}{*}{ EG } & Pre & 12 & $61.92 \pm 3.25$ & \multirow[t]{2}{*}{0.66} \\
\hline & & Post & 12 & $62.67 \pm 2.98$ & \\
\hline & \multirow[t]{2}{*}{ HG } & Pre & 10 & $55.40 \pm 2.74$ & \multirow[t]{2}{*}{0.84} \\
\hline & & Post & 10 & $55.10 \pm 2.14$ & \\
\hline & \multirow[t]{2}{*}{$\mathrm{EH}$} & Pre & 14 & $59.64 \pm 2.53$ & \multirow[t]{2}{*}{0.22} \\
\hline & & Post & 14 & $61.93 \pm 3.77$ & \\
\hline & \multirow[t]{2}{*}{$\mathrm{HH}$} & Pre & 12 & $58.83 \pm 2.10$ & \multirow[t]{2}{*}{0.02} \\
\hline & & Post & 12 & $62.45 \pm 2.27$ & \\
\hline
\end{tabular}


A

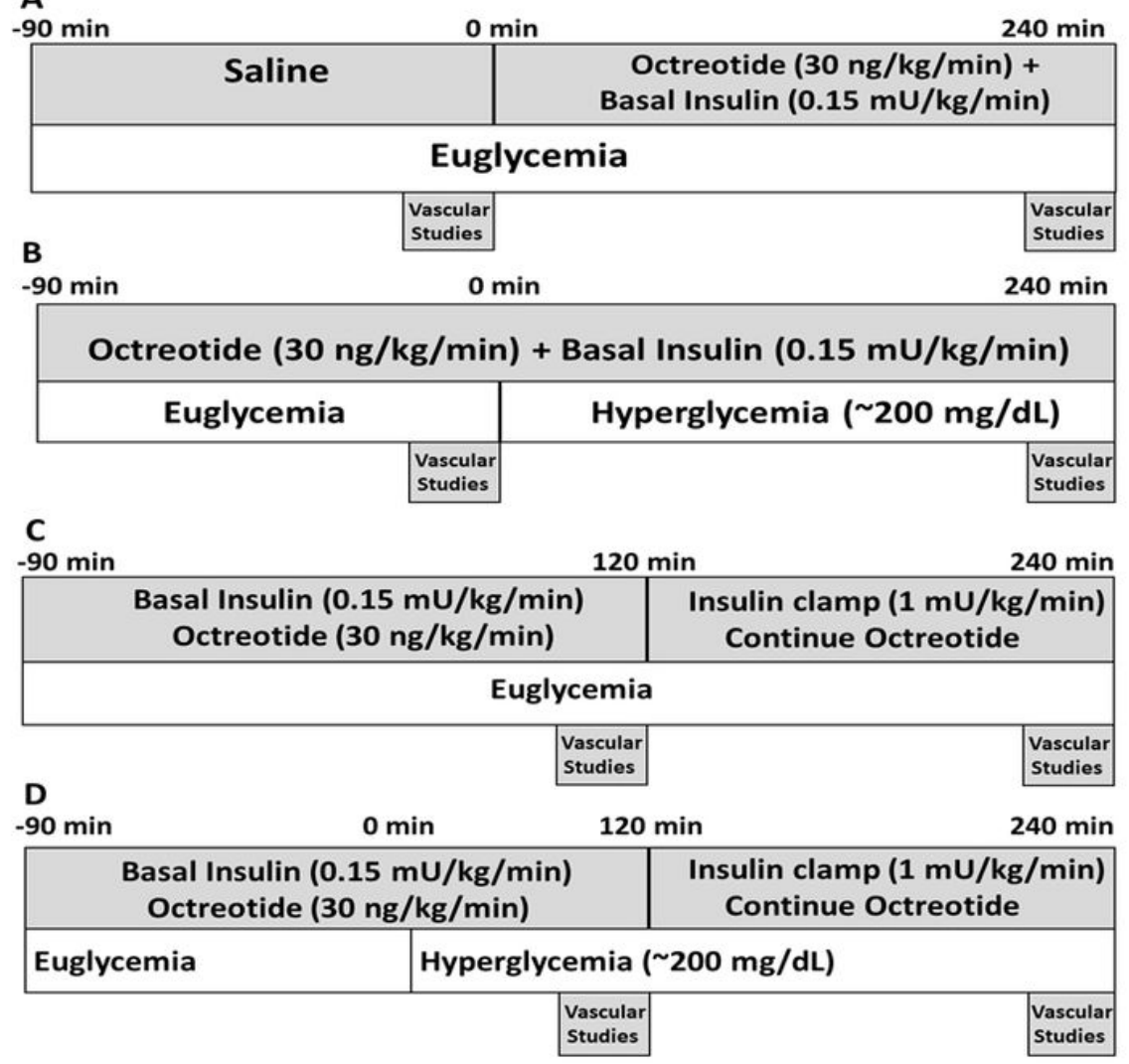

\section{Figure 1}

Experimental protocols. $(A=$ euglycemia; $B=$ hyperglycemia; $C=$ euglycemic-hyperinsulinemia; $D=$ hyperglycemic-hyperinsulinemia). 
A

Plasma Glucose
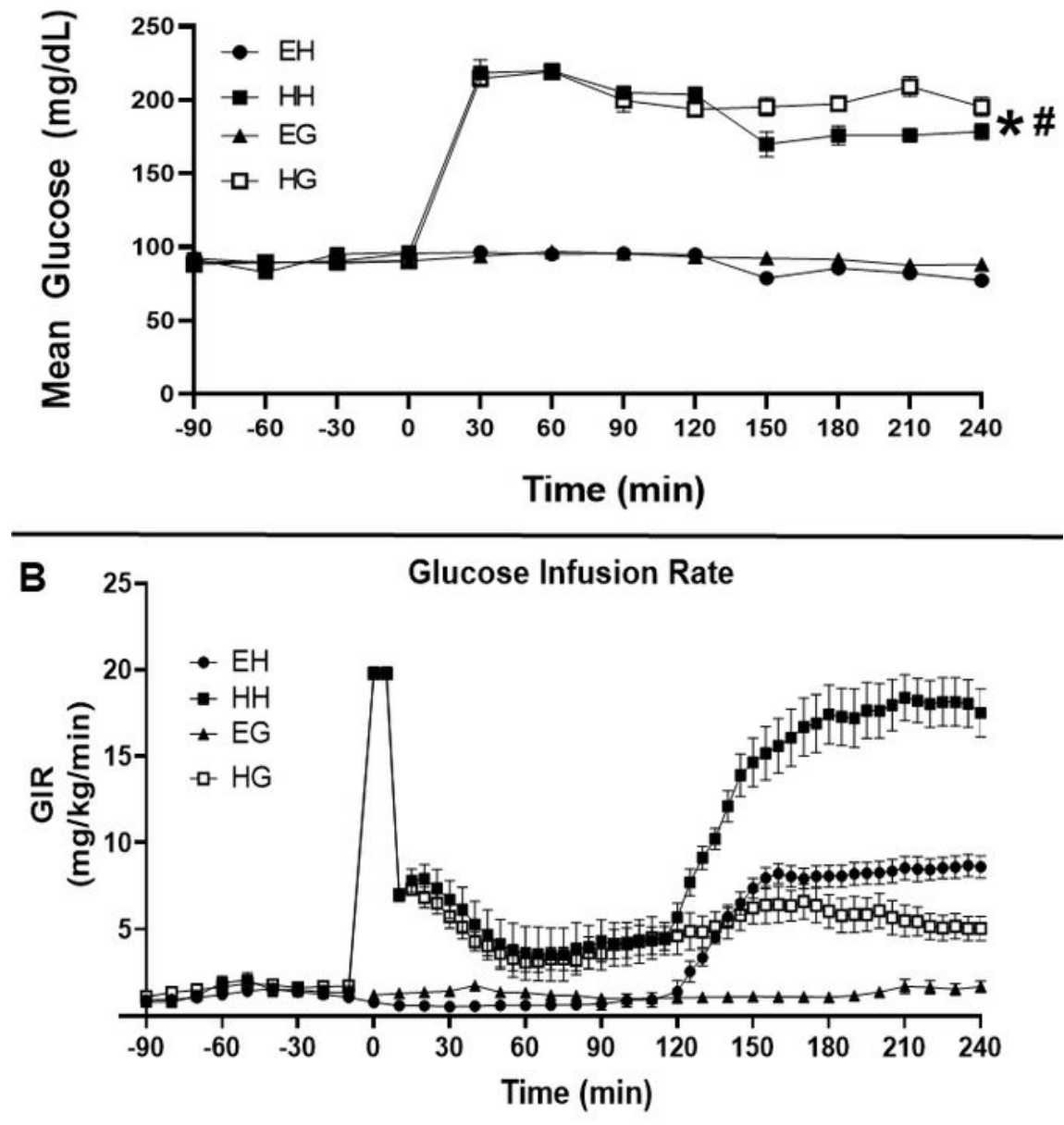

C

\section{Plasma Insulin}

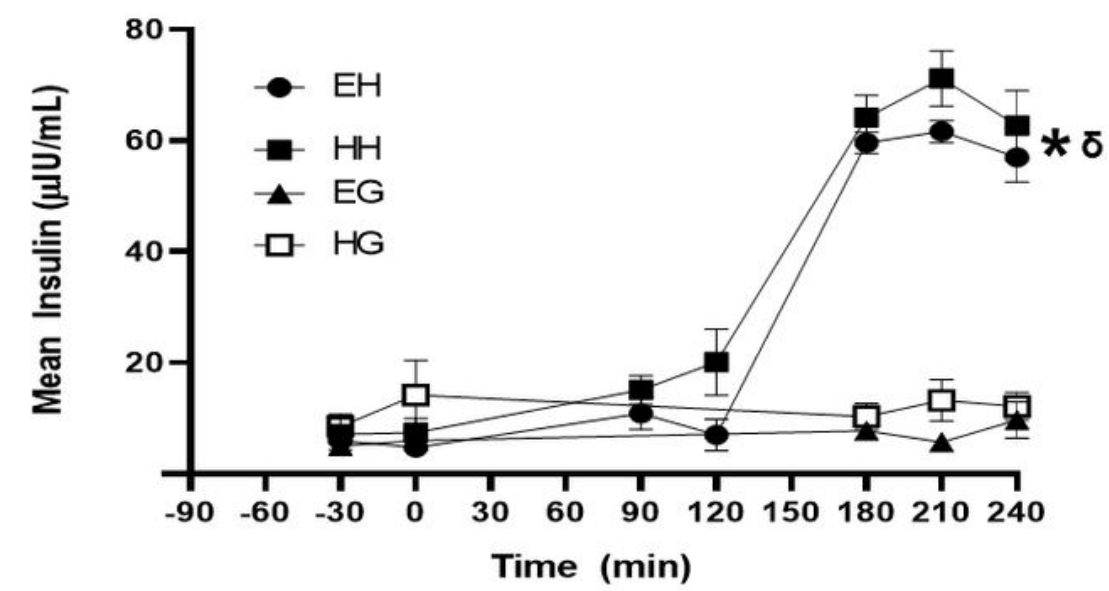

Figure 2

Time course for mean plasma glucose (Panel A), mean glucose infusion rate (Panel B), and mean plasma insulin (Panel $\mathrm{C}$ ) throughout each infusion protocol. (Min= minutes; $\mathrm{GIR}=$ glucose infusion rate; $\mathrm{EG}=$ euglycemia; $\mathrm{HG}=$ hyperglycemia; $\mathrm{EH}=$ euglycemic-hyperinsulinemia; $\mathrm{HH}=$ hyperglycemichyperinsulinemia). ${ }^{*} p<0.001$ when compared to baseline. $\# p<0.01$ when compared to EG or EH. $\delta p<0.001$ when compared to EG or HG. 

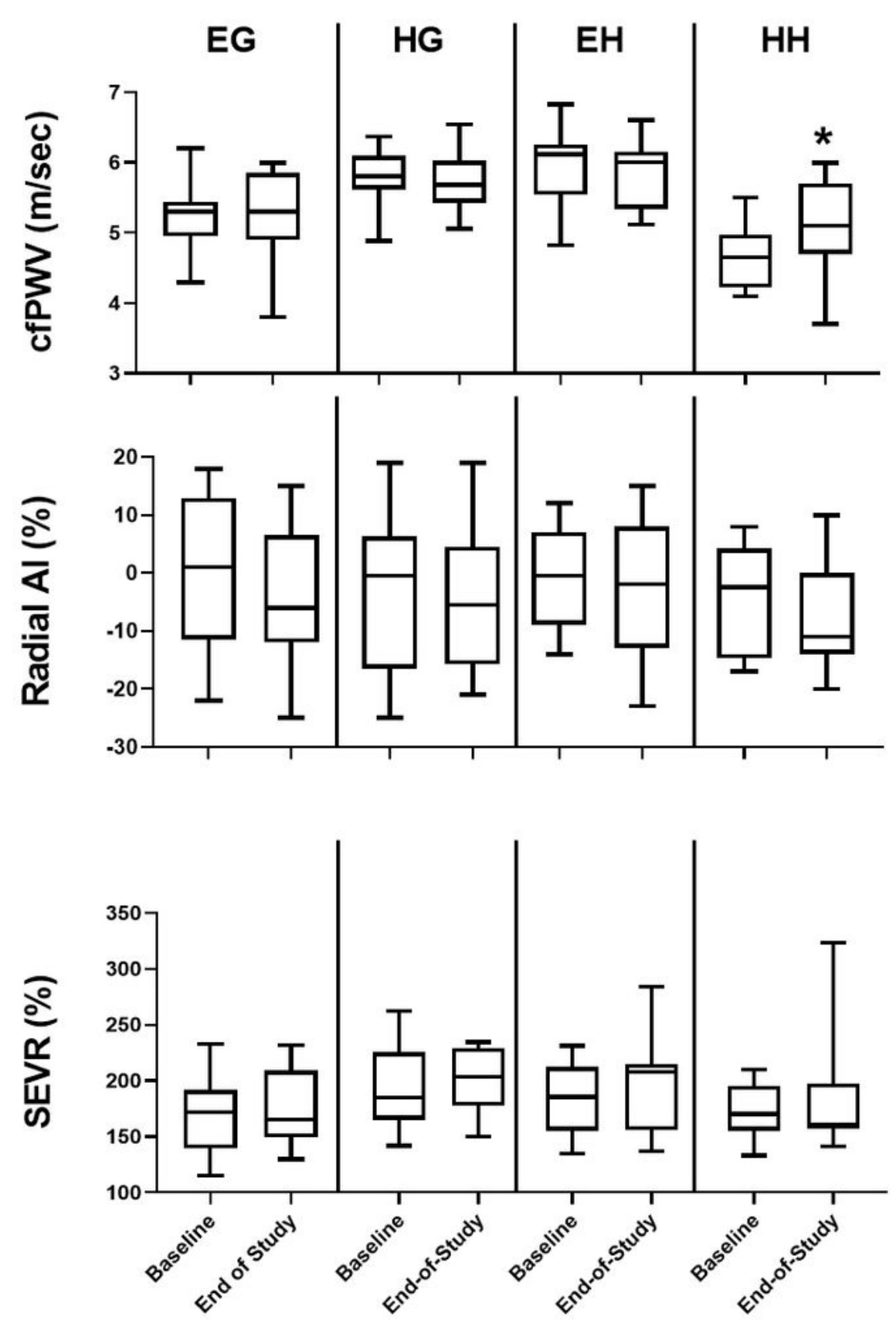

\section{Figure 3}

Boxplots detailing pre-intervention (baseline) and post-intervention (end of study) changes in cfPWV (Panel A), radial AI (Panel B), and SEVR (Panel C) within each protocol. Boxplots present five-point data summary (i.e., minimum, first quartile, median, third quartile, and maximum values). (cfPWV= carotidfemoral pulse wave velocity; $\mathrm{Al}=$ augmentation index; $\mathrm{SEVR}=$ subendocardial viability ratio; $\mathrm{EG}=$ 
euglycemia; $\mathrm{HG}=$ hyperglycemia; $\mathrm{EH}=$ euglycemic-hyperinsulinemia; $\mathrm{HH}=$ hyperglycemichyperinsulinemia). ${ }^{\star} \mathrm{p}<0.03$ when compared to baseline.

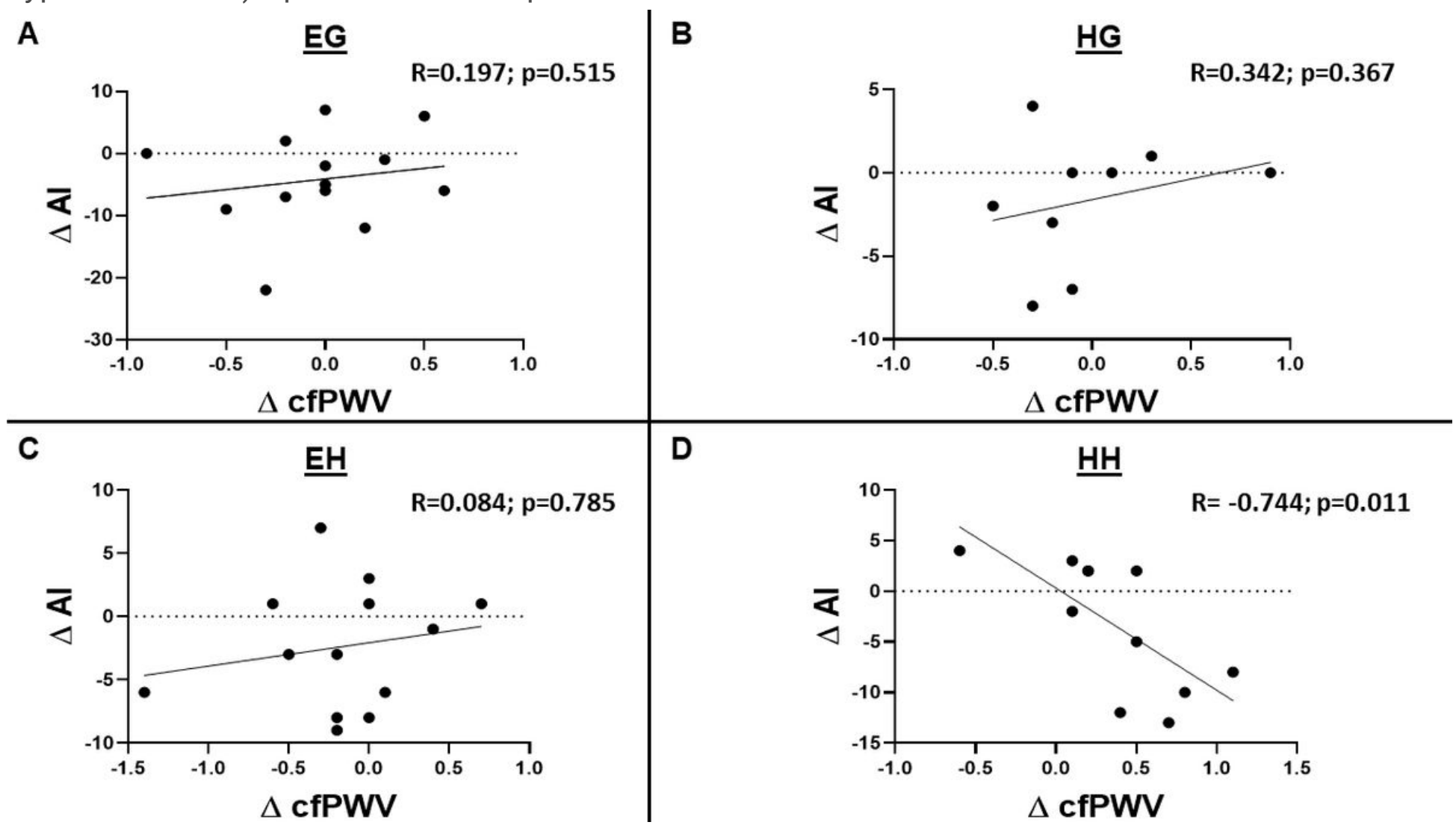

Figure 4

Relationship between change in cfPWV and change in Al during euglycemia (Panel A), hyperglycemia (Panel B), euglycemic-hyperinsulinemia (Panel C), and hyperglycemic-hyperinsulinemia (Panel D). Spearman's correlation was used to evaluate the relationship between variables. Linear regression was used to generate line of best fit. cfPWV is expressed in $\mathrm{m} / \mathrm{sec}$ while radial $\mathrm{Al}$ is expressed as percentage. ( $E G=$ euglycemia; $\mathrm{HG}=$ hyperglycemia; $\mathrm{EH}=$ euglycemic-hyperinsulinemia; $\mathrm{HH}=$ hyperglycemichyperinsulinemia). 